\title{
Exochelin-mediated Iron Acquisition by the Leprosy Bacillus, Mycobacterium leprae
}

\author{
By RICHARD M. HALL† AND COLIN RATLEDGE* \\ Department of Biochemistry, University of Hull, Hull HU6 7RX, UK
}

(Received 19 May 1986; revised 25 July 1986)

\begin{abstract}
Exochelins, water-soluble siderophores of mycobacteria, were isolated and partially purified from culture filtrates of iron-deficiently grown cultures of Mycobacterium neoaurum NCTC 10439 and an armadillo-derived Mycobacterium (ADM 8563). Two biologically active fractions mediating iron uptake were isolated from each bacterium which not only were able to transport iron into the producing organism but also into suspensions of Mycobacterium leprae isolated from armadillo liver. The rate of exochelin-mediated iron uptake into $M$. leprae was about $1.5 \%$ of the rate observed into the producing organisms. The process of iron uptake appears to be by facilitated diffusion as it was not inhibited by $\mathrm{HgCl}_{2}, \mathrm{NaN}_{3}, \mathrm{KCN}$, dinitrophenol or carbonyl cyanide $m$-chlorophenylhydrazone. Since no uptake of iron occurred into iron-sufficient ADM cells, this may indicate that $M$. leprae, as recovered from an animal tissue, had been growing iron-deficiently in order for iron uptake to have been demonstrated in vitro.
\end{abstract}

\section{INTRODUCTION}

Although some 15 to 20 million people world-wide suffer from leprosy, our detailed knowledge of Mycobacterium leprae, the causative organism of this disease, remains incomplete since no bacterium showing a close chemical, pathological or immunological similarity to it has ever been grown on artificial media (Stewart-Tull, 1982). A major step forward in experimental leprosy occurred with the demonstration that the nine-banded armadillo (Dasypus novemcinctus Linn.) could be used for the cultivation in vivo of M. leprae (Storrs, 1971, 1974; Storrs et al., 1978). However, in addition to the leprosy bacillus infected armadillo tissue may contain other mycobacteria which can be grown in vitro (Portaels \& Pattyn, 1982; Portaels et al., 1982, 1985). These are the so-called 'armadillo-derived mycobacteria' (ADMs). Their role in leprosy, if any, is unknown as is their origin and possible relationship to $M$. leprae, though it appears unlikely that ADMs are derived from $M$. leprae.

The acquisition of iron from host tissues probably occupies a central role in the development of a bacterial pathogen in vivo (Barclay, 1985; Griffiths, 1985; Neilands et al., 1985). As little unchelated iron exists within the host, invading bacteria must obtain their iron from circulating iron-containing proteins, such as transferrin or lactoferrin, or from the iron-storage protein ferritin. Like many other bacteria, mycobacteria synthesize low molecular mass siderophores, termed exochelins, which can remove iron from these molecules (Macham et al., 1975) and thus provide a means for iron acquisition in mycobacteria growing both in vitro and in vivo (Barclay \& Ratledge, 1983). Exochelins are of unknown structure but are probably pentapeptides with $N$ - $\varepsilon-$ hydroxyornithines providing part or all of the chelating centre (A. J. M. Messenger, unpublished work). Although exochelins are isolated from the culture medium of mycobacteria grown under

$\dagger$ Present address: Glaxo Group Research, Department of Biotechnology, Greenford, Middlesex UB6 0HE, UK.

Abbreviation: ADM, armadillo-derived Mycobacterium. 
conditions of iron-limitation (about $0.05 \mu \mathrm{g} \mathrm{Fe} \mathrm{ml}^{-1}$ ) (Macham et al., 1975; Messenger et al., 1986; Stephenson \& Ratledge, 1980), it is impossible to assess the production of such compounds by $M$. leprae because of its failure to grow in vitro. Already, we have tested the ability of the leprosy bacillus isolated from armadillo tissue, to acquire iron from exochelins isolated from four other species of mycobacteria: $M$. vaccae, $M$. bovis BCG, $M$. smegmatis and $M$. neoaurum, and have found that the process was relatively specific in that only the exochelin from $M$. neoaurum was active in this capacity (Hall et al., 1983). Although $M$. leprae might be related to a rapidly growing mycobacterium (Stanford et al., 1975), it seems highly unlikely that a soil saprophyte, such as $M$. neoaurum, could come into contact with, and supply iron to, $M$. leprae in vivo. Consequently, we suggest that the leprosy bacillus must either itself synthesize exochelins or have a more direct access to a supply of exochelins than chance contact with a soil mycobacterium would permit. We have, therefore, extended our previous work with the exochelins of $M$. neoaurum (Hall et al., 1983) and are now able to show that similar if not identical exochelins are elaborated by the ADMs which also function in iron uptake into $M$. leprae. The process of iron acquisition by $M$. leprae has been studied in more detail and we are able to advance a hypothesis for the mechanism by which the leprosy bacillus is able to acquire iron.

\section{METHODS}

Organisms and growth. Armadillo-derived mycobacterium (ADM) no. 8563 was kindly supplied by Dr F. Portaels, Antwerp, Belgium. It appears to be a representative strain of a new species of Mycobacterium (Hall \& Ratledge, 1985; Portaels et al., 1986). Both it and M. neoaurum NCTC 10439 were grown in a rotary-shaking incubator in glycerol/asparagine liquid medium under either iron-deficient conditions $\left(0.05 \mu \mathrm{g} \mathrm{Fe} \mathrm{ml}{ }^{-1}\right)$ or ironsufficient conditions $\left(2 \mu \mathrm{g} \mathrm{Fe} \mathrm{ml} l^{-1}\right)$ for $8 \mathrm{~d}$ (Ratledge \& Hall, 1971). M. leprae was isolated in the laboratory from frozen $\left(-80^{\circ} \mathrm{C}\right)$ armadillo livers, kindly provided via LEPRA and the Medical Research Council, following the procedure of Draper (World Health Organization, 1980) and the organisms were then used immediately.

Exochelins: isolation and purification. Exochelins were isolated from culture filtrates of iron-deficiently grown $\boldsymbol{M}$. neoaurum and ADM, and then partially purified by anion-exchange chromatography following the procedures of Macham et al. (1975). These are referred to as partially purified, unfractionated ferri-exochelins. Further purification was achieved by cation-exchange chromatography using a $250 \times 15 \mathrm{~mm}$ column packed with BioRad AG50W-X4 (200-400 mesh; $\mathrm{NH}_{4}^{+}$-form) and a gradient of $0 \cdot 1 \mathrm{M}-\mathrm{NH}_{4} \mathrm{OH}$ with acetic acid, $\mathrm{pH} 6 \cdot 0$, to $1 \cdot 0 \mathrm{M}^{-}$ $\mathrm{NH}_{4} \mathrm{OH}$ with acetic acid, $\mathrm{pH} 9 \cdot 0$, as eluant. The absorbance of the eluate was monitored continuously at $260 \mathrm{~nm}$ and $3 \mathrm{ml}$ fractions collected. A $2 \mathrm{ml}$ sample of each of the two major fractions (see Results) was made into the desferri-form by the method of Macham et al. (1977), the desferri-exochelin being evaporated to dryness and subsequently labelled with $200 \mu \mathrm{l}^{55} \mathrm{FeCl}_{3}$ [specific activity $1 \mu \mathrm{Ci}(\mu \mathrm{g} \mathrm{Fe})^{-1}$ ] in water. After allowing the mixture to stand for $16 \mathrm{~h}$, unchelated iron was removed by passage through Sephadex G-10 $(180 \times 10 \mathrm{~mm})$. Subsequent purification was by applying approximately $1 \mathrm{ml}$ samples (approximately $340000 \mathrm{c.p} . \mathrm{m}$.) to a molecular sieve column $(850 \times 20 \mathrm{~mm})$ of Biogel $\mathrm{P}_{4}$ and eluting with water. Fractions of approximately $2 \mathrm{ml}$ were collected and the radioactivity in $500 \mu \mathrm{l}$ of each fraction was counted in a scintillation counter. Further purification of purified ferri-exochelins was by thin-layer chromatography using cellulose sheets (Eastman Kodak), $200 \times 200 \mathrm{~mm}$, with butanol/glacial acetic acid/water $(12: 5: 2$, by vol.) as solvent. Exochelins were detected by spraying the sheets with ninhydrin $\left(0.1 \%\right.$ in acetone) before heating at $95^{\circ} \mathrm{C}$ for 2 to $3 \mathrm{~min}$.

Uptake of ${ }^{55} \mathrm{Fe}$-exochelins. Procedures for the uptake of ${ }^{55} \mathrm{Fe}$-exochelins into washed cells of $\mathrm{M}$. neoaurum and ADM suspended in $50 \mathrm{mM}-\mathrm{KH}_{2} \mathrm{PO}_{4} / \mathrm{NaOH}$ buffer, $\mathrm{pH} 7 \cdot 1$, were described previously (Macham et al., 1977; Stephenson \& Ratledge, 1980). Uptake into similar suspensions of $M$. leprae was essentially the same though with precautions being taken to prevent microbial contamination and evaporation over the longer incubation times; the protocol was described by Hall et al. (1983). Experiments for the uptake of iron into $M$. neoaurum and ADM were done at least twice and results are quoted for a typical experiment; experiments with $M$. leprae were usually only done once due to severe limitation in supply of bacteria.

Preparation of other iron chelates. Ferri-salicylate and ferri-EDTA were prepared as $1: 3$ complexes; ferri-citrate was prepared as a $1: 200$ complex to achieve soluble iron at pH 7.0 as previously described (Messenger \& Ratledge, 1982).

\section{RESULTS}

\section{Biological activities of unfractionated exochelins}

Initial examination of the biological activity of the partially purified, unfractionated exochelins from ADM 8563 and $M$. neoaurum showed that these were able to donate iron (as 

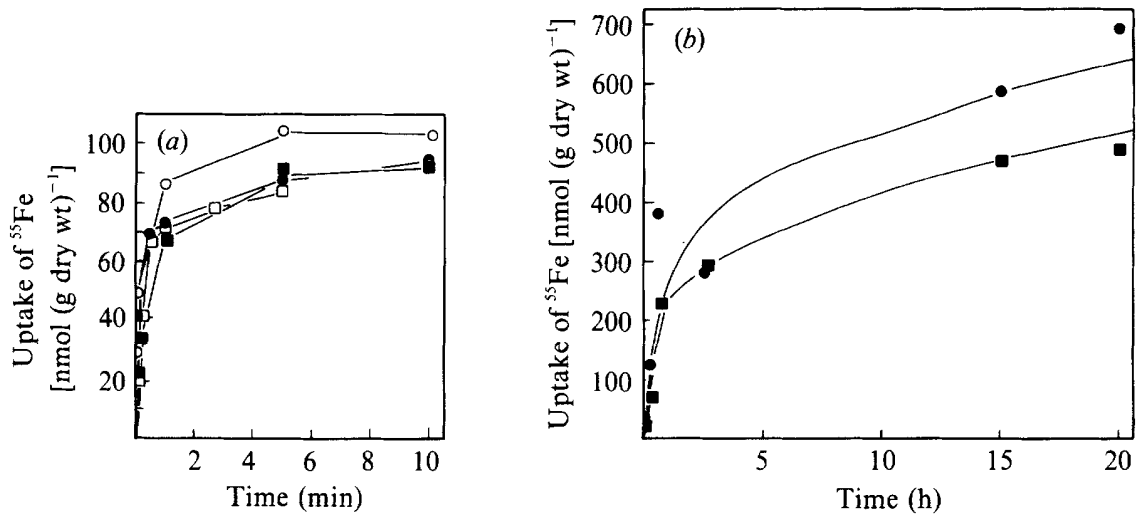

Fig. 1. Exochelin-mediated iron uptake. (a) Uptake of ${ }^{55} \mathrm{Fe}$, at $1 \mu \mathrm{M}$, complexed to unfractionated partially purified exochelins isolated from ADM 8563, by suspensions of iron-deficiently grown cells of the same organism (O) and by $M$. neoaurum NCTC 10439 grown similarly $(O)$; uptake of ${ }^{55} \mathrm{Fe}$ exochelins (also $1 \mu \mathrm{M}$ ) isolated from $M$. neoaurum by $M$. neoaurum ( $\square$ ) and by ADM suspensions prepared similarly ( $\mathbf{\square}$. (b) Uptake of ${ }^{55} \mathrm{Fe}$, at $10 \mu \mathrm{M}$, complexed to the same exochelins, by a suspension of $M$. leprae recovered from infected armadillo liver: 0 , exochelins from ADM;, exochelins from $M$. neoaurum. (Note that different concentrations of ${ }^{55} \mathrm{Fe}$-exochelin were used in the two sets of experiments.)

${ }^{55} \mathrm{Fe}$ ) to both the producing cells and to each other at equal rates (Fig. $1 a$ ). Also, the exochelins from ADM and $M$. neoaurum both donated iron at equal rates to $M$. leprae cells recovered from armadillo tissue, though over a longer period (Fig. $1 b$ ) than had been taken with the producing organisms. (It should be noted that experiments with $M$. leprae were done with $10 \mu \mathrm{M}^{55} \mathrm{Fe}$ exochelin, compared to $1 \mu \mathrm{M}$ for $M$. neoaurum and $M$. vaccae.)

The process of exochelin-mediated iron uptake into $M$. neoaurum was shown by Hall et al. (1983) not to be inhibited by $\mathrm{HgCl}_{2}(0.1 \mathrm{~mm}), \mathrm{NaN}_{3}(30 \mathrm{~mm})$ or dinitrophenol ( $\left.2 \mathrm{~mm}\right)$. Similarly, uptake into $\mathrm{ADM}$ was not inhibited by $\mathrm{NaN}_{3}(30 \mathrm{mM}), \mathrm{KCN}(10 \mathrm{mM})$, carbonyl cyanide $m$ chlorophenylhydrazone $(0.1 \mathrm{mM})$ or $\mathrm{HgCl}_{2}(0.1 \mathrm{mM})$. Both processes therefore appear to be mediated by facilitated diffusion rather than by active transport.

\section{Fractionation of exochelins}

Subsequent fractionation of the exochelins from ADM 8563 and $M$. neoaurum was done on non-radioactive ferri-complexes by cation exchange chromatography (Fig. $2 a$ ). Each mixture had two components with equivalent retention volumes; a third, smaller component was also recognized in the siderophores from $M$. neoaurum. Of the two similar fractions, the one eluting first (fraction 1) in each case was about four times more active for ${ }^{55} \mathrm{Fe}$ uptake into $M$. neoaurum, as test organism, than the second fraction. The third, minor fraction from $M$. neoaurum was not active for the uptake of iron into $M$. neoaurum and was consequently not examined further. Further purification of the exochelins was therefore continued only with the first fraction from each organism. Each fraction 1 was chromatogrammed as the ferri-complex by gel filtration which separated it into three further components (as shown by absorbance at $260 \mathrm{~nm}$ ), only two of which were chelators of $\mathrm{Fe}$ (III) (see Fig. $2 b$ ). These components are termed $1 \mathrm{~A}$ and $1 \mathrm{~B}$. Further cellulose thin-layer chromatography failed to differentiate them, though it did reveal that both fractions were still not single components as there were two ninhydrin positive materials in each fraction $1 \mathrm{~A}$, and four (two major and two minor) similarly reactive compounds in each fraction $1 \mathrm{~B}$.

\section{Activities of exochelins $I A$ and $I B$}

Both exochelin 1A and 1B were biologically active siderophores in that they both transported ${ }^{55} \mathrm{Fe}$ into ADM and $M$. neoaurum, irrespective of the origin of the exochelin, at the same rate 


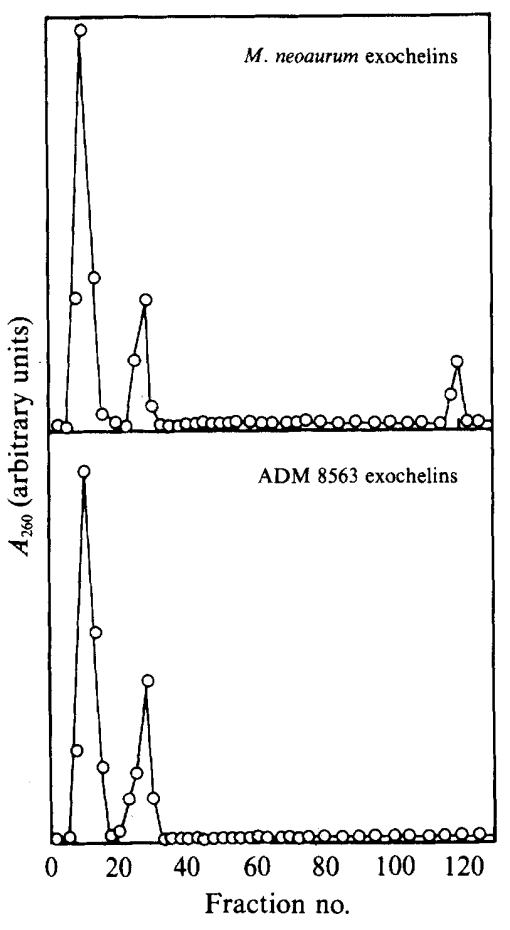

Fig. 2(a)

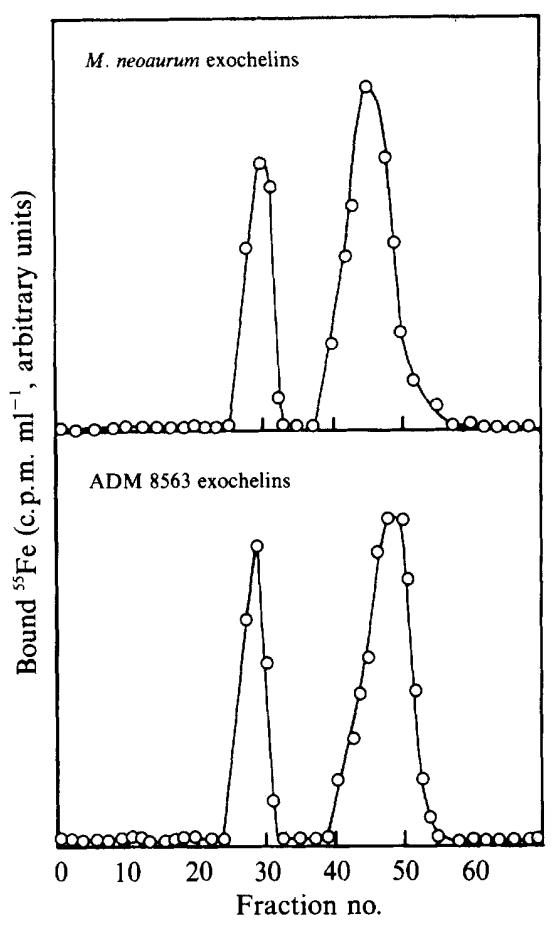

Fig. $2(b)$

Fig. 2. (a) Fractionation of the partially purified ferri-exochelins used in Fig. 1 by cation-exchange chromatography (BioRad AG50W-X4) using a gradient of $0.1 \mathrm{M}-\mathrm{NH}_{4} \mathrm{OH} /$ acetic acid, $\mathrm{pH} 6.0$, to $1.0 \mathrm{M}$ $\mathrm{NH}_{4} \mathrm{OH} /$ acetic acid, $\mathrm{pH} 9 \cdot 0 . A_{260}$ was monitored continuously. Fraction 1 is the one eluting first in each case; fraction 2 is the one eluting second. (b) Resolution of Fraction 1 (from Fig. 2a) after conversion to the ${ }^{55} \mathrm{Fe}$-form, into components $1 \mathrm{~A}$ and $1 \mathrm{~B}$ by chromatography through a Biogel $\mathbf{P}_{4}$ column eluting with water as solvent.
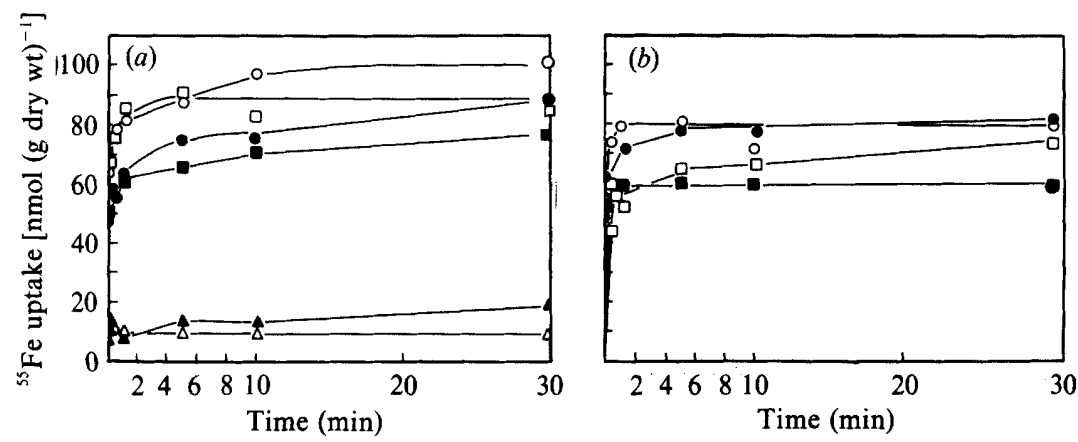

Fig. 3. Uptake of purified exochelins into ADM 8563 and $M$. neoaurum. (a) Uptake of ${ }^{55} \mathrm{Fe}$, at $1 \mu \mathrm{M}$, complexed to exochelin fraction 1A; $(b)$ uptake from fraction 1B. Exochelin isolated from $M$, neoaurum by washed suspensions of iron-deficiently grown cells of $M$. neoaurum ( $\square)$ and of ADM ( $\square$ ); exochelin isolated from ADM by similar suspensions of $\mathrm{ADM}(O)$ and of $M$. neoaurum (O). Also included in $(a)$, uptake of ${ }^{55} \mathrm{Fe}$, at $1 \mu \mathrm{M}$, complexed to purified exochelin (fraction 3) from $M$. smegmatis by $\operatorname{ADM}(\triangle)$ and $M$. neoaurum $(\boldsymbol{A})$ cell suspensions.

(Fig. $3 a, b$ ). The rate of uptake of iron was similar to that observed with the initial unfractionated exochelins (see Fig. 1).

Although the process of iron uptake as mediated by the exochelins appears to be by facilitated diffusion, it was, nevertheless, specific for the exochelins from $M$. neoaurum and ADM as 


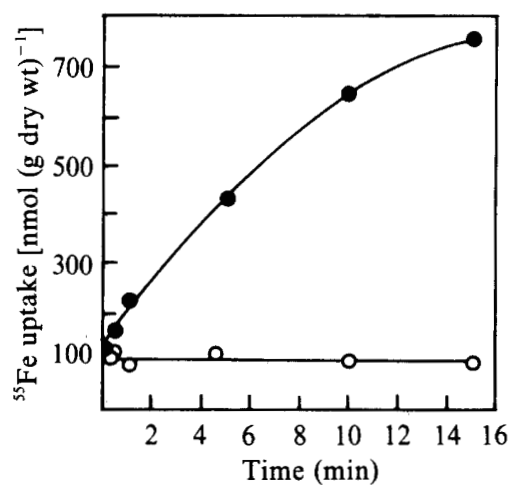

Fig. 4

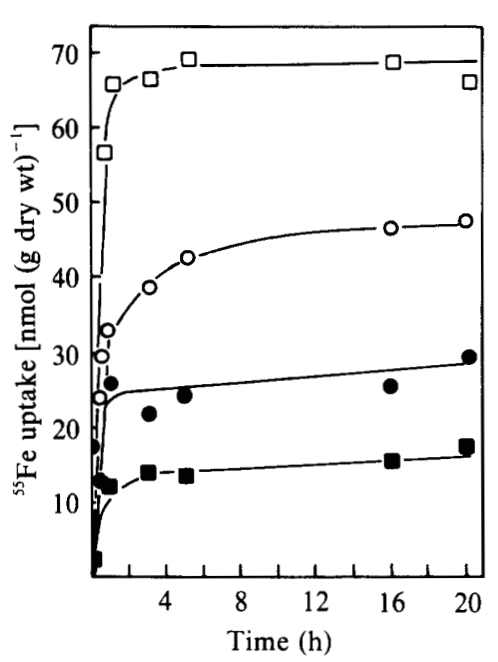

Fig. 5

Fig. 4. ${ }^{55} \mathrm{Fe}$ uptake, at $10 \mu \mathrm{M}$, complexed to exochelin fraction 1 (A and B) - see Fig. 2(a) - prepared from ADM 8563 into iron-deficiently grown cells of ADM (O) and into iron-sufficiently $\left(2.0 \mu \mathrm{g} \mathrm{Fe} \mathrm{m}^{-1}\right)$ grown cells $(\mathrm{O})$.

Fig. 5 . ${ }^{55} \mathrm{Fe}$ uptake, at $1 \mu \mathrm{M}$, complexed to purified exochelin fractions, $1 \mathrm{~A}$ and $1 \mathrm{~B}$ (see Fig. $2 a$ ) prepared from ADM 8563 ( $\bigcirc$ and $\bigcirc$, respectively) and $M$. neoaurum ( $\square$ and $\square$, respectively) by $M$. leprae cell suspensions isolated from armadillo liver.

uptake of ${ }^{55} \mathrm{Fe}$ from the biologically active exochelin isolated from M. smegmatis (termed MS-3; see Macham et al., 1977) was almost negligible into both organisms (see Fig. $3 a$ ). Furthermore, the status of the recipient cells was important as no uptake of ${ }^{55} \mathrm{Fe}$ from exochelin fraction 1 $(A+B)$ could be demonstrated into iron-sufficiently grown cells of ADM (Fig. 4).

\section{Iron uptake into $M$. leprae}

Exochelin 1A and $1 \mathrm{~B}$ from either ADM or $M$. neoaurum were each capable of donating iron to $M$. leprae; the process was essentially complete after $6 \mathrm{~h}$ (Fig. 5). Although both the exochelin $1 \mathrm{~B}$ fractions gave greater uptakes than the $1 \mathrm{~A}$ fractions, this might not be significant. (Due to the severe shortage of infected armadillo liver tissue, it was not possible to confirm this difference by further experiments but if the exochelins from ADM and $M$. neoaurum are identical, then the results given in Fig. 5 may be taken as arising from duplicate experiments.) Uptake of ${ }^{55} \mathrm{Fe}$ from both exochelins $1 \mathrm{~A}$ and $1 \mathrm{~B}$ (from $M$. neoaurum) into $M$. leprae was not affected by sodium azide (at $30 \mathrm{~mm}$ ).

When other iron complexes were presented to a suspension of $M$. leprae and ${ }^{55} \mathrm{Fe}$ uptake followed over $3 \mathrm{~h}$, the amount of ${ }^{55} \mathrm{Fe}$ taken up from ferri-salicylate was $15 \%$ of that attained with exochelin $1(\mathrm{~A}+\mathrm{B}$ combined) over the same period; from ferri-citrate, uptake was about $10 \%$ of the exochelin-mediated value and uptake from ferri-EDTA was virtually nil. However, citrate and salicylate, but not EDTA, could donate iron into iron-deficiently grown ADM cells at about the same rate as observed with exochelin $1 \mathrm{~A}$.

\section{DISCUSSION}

The exochelins described here from $M$. neoaurum and ADM 8563 appear to be distinct from those described earlier from M. smegmatis and M. vaccae (Macham et al., 1975; Messenger et al., 1986) and from BCG, M. tuberculosis and M. avium (Stephenson \& Ratledge, 1980; Barclay \& Ratledge, 1983). The exochelins from $M$. smegmatis and $M$. vaccae participate in an active iron transport process, i.e. a process inhibitable by uncouplers of oxidative phosphorylation and energy poisons, whereas the slow-growing species (BCG, M. tuberculosis and M. avium) yield 
exochelins which are soluble in chloroform and mediate iron uptake by a facilitated diffusion process. The ADM and $M$. neoaurum exochelins, on the one hand, are similar in their watersolubility to the former siderophores, but on the other, mediate iron uptake in a manner similar to that of the slow-growing species. Moreover, exochelins from $M$. smegmatis are not used by ADM or $M$. neoaurum (see Fig. $3 b$ ) or indeed by $M$. leprae, a point that was established by Hall $e t$ al. (1983).

The two biologically active exochelin fractions (1A and 1B) were each elaborated by $M$. neoaurum and ADM 8563 and are probably the same materials being produced in each organism. Although the exochelins from the two organisms could not be differentiated either biologically or chromatographically, the two bacteria are readily distinguished by conventional taxonomy (Portaels et al., 1986) as well as by differences in their mycobactins (Hall \& Ratledge, 1985).

Perhaps of considerable significance was the observation that exochelin-mediated iron uptake into ADM was dependent upon the cells being previously grown under iron-deficient conditions (Fig. 4). As the same process of iron uptake could be successfully demonstrated to occur with $M$. leprae isolated from armadillo tissue, this would suggest that $M$. leprae itself had probably grown iron-deficiently within the host tissue. The evidence that other pathogenic bacteria also grow in vivo in an iron-deficient state has been recently reviewed by Griffiths (1985).

Although the requirements of $M$. leprae for iron are not known, its ability to take up iron from exochelins synthesized by an ADM strain that had been isolated as a commensal Mycobacterium along with $M$. leprae is intriguing. This is especially so since these mycobacteria might be present in numbers exceeding $10 \%$ of the total acid-fast bacilli isolated from an infected armadillo liver (Portaels \& Pattyn, 1982; Portaels et al., 1982). They would therefore be sufficiently numerous to provide enough exochelin, and thus iron, for not only themselves to grow in vivo but also the leprosy bacillus itself. Indeed, the hypothesis has already been put forward by Segal (1984) that $M$. leprae might be growing 'as a mixed infection, consisting of definite fixed species existing in commensal or symbiotic association'. Although our results could support this proposal, it is equally tenable that $M$. leprae synthesizes its own exochelins and we have merely detected similar siderophores in other mycobacteria.

The exochelin-mediated uptake of iron into $M$. leprae would appear to be by a facilitated diffusion process with there being little evidence that uptake can be sustained by other ironcomplexing agents such as citrate or salicylate. Citrate and salicylate, however, appear to be effective donors of iron not only into ADM 8563 but also into M. vaccae (Messenger et al., 1986) and $M$. smegmatis (Messenger \& Ratledge, 1982).

The ability of exochelins from $M$. neoaurum to mediate iron uptake into $M$. leprae is possibly fortuitous although the organism was originally chosen for examination (Hall et al., 1983) as it is taxonomically close to $M$. vaccae (Goodfellow \& Wayne, 1982), which itself had once been considered as taxonomically close to M. leprae (Stanford et al., 1975; Stanford \& Rook, 1976). M. vaccae does not, however, show any similarity to $M$. leprae with regard to its iron uptake processes. Whether the newly isolated strain of ADM, which probably represents a new species or taxon of Mycobacterium (Portaels et al., 1986), is related to M. leprae is unknown.

Although the inability to culture $M$. leprae in vitro is most probably a multifunctional problem, we would propose that it would probably be an advantage to incorporate the exochelins from ADM or $M$. neoaurum into any future in vitro growth experiments with the leprosy bacillus since the acquisition of iron is of such undeniable importance to pathogens (Barclay, 1985; Griffiths, 1985). Also, with respect to iron metabolism, both ADM 8563 and $M$. neoaurum can act as excellent model systems for future experimentation as supplies of $M$. leprae are never plentiful. A deeper understanding of the mechanism of iron uptake - including the participation of other components in the process - may therefore be usefully unravelled in the more accessible and non-pathogenic strains.

We thank Janet Stephenson for technical assistance and Dr Francoise Portaels, Antwerp, Belgium, for providing ADM no. 8563 amongst other strains. This work was supported by a grant from the Medical Research 
Council to C.R. We also acknowledge the fundamental support of LEPRA who provide the funds for maintaining the colony of infected armadillos at a separate location.

\section{REFERENCES}

Barclay, R. (1985). The role of iron in infection. Medical Laboratory Sciences 42, 166-177.

BARClay, R. \& RatledGe, C. (1983). Iron-binding compounds of Mycobacterium avium, $M$. intracellulare, $M$. scrofulaceum and mycobactin-dependent $M$. paratuberculosis and $M$. avium. Journal of Bacteriology 153, 1138-1146.

Goodfellow, M. \& WAYNe, L. (1982). Taxonomy and nomenclature. In The Biology of the Mycobacteria, vol. 1, pp. 471-521. Edited by C. Ratledge \& J. Stanford. London: Academic Press.

GRIFFITHS, E. (1985). Candidate virulence markers. In The Virulence of Escherichia coli (SGM Special Publication no. 13), pp. 193-226. Edited by M. Sussman. London: Academic Press.

HALl, R. M. \& RatledGe, C. (1985). Mycobactins in the classification and identification of armadilloderived mycobacteria. FEMS Microbiology Letters 28, 243-247.

Hall, R. M., Wheeler, P. R. \& Ratledge, C. (1983). Exochelin-mediated iron uptake into Mycobacterium leprae. International Journal of Leprosy 51, 490-494.

Macham, L. P., Ratledge, C. \& Norton, J. C. (1975). Extracellular iron acquisition by mycobacteria: role of the exochelins and evidence against the participation of mycobactin. Infection and Immunity 12, 12421251.

Macham, L. P., Stephenson, M. C. \& Ratledge, C. (1977). Iron transport in Mycobacterium smegmatis: the isolation, purification and function of exochelin MS. Journal of General Microbiology 101, 41-49.

Messsenger, A. J. M. \& Ratledge, C. (1982). Iron transport in Mycobacterium smegmatis: uptake of iron from ferric citrate. Journal of Bacteriology 149, 131-135.

Messenger, A. J. M., Hall, R. M. \& Ratledge, C. (1986). Iron uptake processes in Mycobacterium vaccae $\mathrm{R} 877 \mathrm{R}$, a Mycobacterium lacking mycobactin. Journal of General Microbiology 132, 845-852.

NeIlands, J. B., Bindereif, A. \& Montgomerie, J. Z. (1985). Genetic basis of iron assimilation in pathogenic Escherichia coli. Current Topics in Microbiology and Immunology 118, 179-195.

Portaels, F. \& Pattyn, S. R. (1982). Growth of mycobacteria in relation to the $\mathrm{pH}$ of the medium. Annales de microbiologie (Institut Pasteur) 133B, 213221.

Portaels, F., Francken, A. \& Pattyn, S. R. (1982). Bacteriological studies of armadillo livers infected with Mycobacterium leprae. Annales de la Société belge de médecine tropicale 62, 233-245.

Portaels, F., De Ridder, K. \& Pattyn, S. R. (1985). Cultivable mycobacteria isolated from organs of armadillo uninoculated and inoculated with $\mathrm{Myco}$ - bacterium leprae. Annales de microbiologie (Institut Pasteur) 136A, 181-190.

Portaels, F., Asselineau, C., Baess, I., Daffé, M., Dobson, G., Draper, P., Gregory, D., Hall, R. M., IMAeda, T., Jenkins, P. A., LANÉElle, M. A., Larsson, L., Magnusson, M., Minnikin, D. E., Pattyn, S. R., Wieten, G. \& Wheeler, P. R. (1986). A cooperative taxonomic study of mycobacteria isolated from armadillos infected with $\mathrm{Myco}$ bacterium leprae. Journal of General Microbiology 132, 2693-2707.

RATLEDGE, C. \& HALL, M. J. (1971). Influence of metal ions on the formation of mycobactin and salicylic acid in Mycobacterium smegmatis grown in staticculture. Journal of Bacteriology 108, 314-319.

SEGAL, W. (1984). Growth dynamics of in vivo and in vitro grown mycobacterial pathogens. In The Mycobacteria-A Sourcebook, part A, pp. 547-573. Edited by G. P. Kubica \& L. G. Wayne. New York: Marcel Dekker.

STANFORD, J. L. \& RooK, G. A. W. (1976). Taxonomic studies on the leprosy bacillus. International Journal of Leprosy 44, 216-221.

Stanford, J., RoOK, G. A. W., Convit, J., Godal, T., Kronvall, G., Rees, R. J. W. \& Walsh, G. P. (1975). Preliminary taxonomic studies on the leprosy bacillus. British Journal of Experimental Pathology 56, 579-585.

Stephenson, M. C. \& Ratledge, C. (1980). Specificity of exochelins for iron transport in three species of mycobacteria. Journal of General Microbiology 116, 521-523.

STEWART-Tull, D. E. S. (1982). Mycobacterium leprae - The Bacteriologist's Enigma. In The Biology of the Mycobacteria, vol. 1, pp. 273-307. Edited by C. Ratledge \& J. L. Stanford. London: Academic Press.

STORRS, E. E. (1971). The nine-banded armadillo: a model for leprosy and other biomedical research. International Journal of Leprosy 39, 703-714.

STORRS, E. E. (1974). The armadillo as an experimental model for the study of human leprosy. Leprosy Review 45, 8-14.

Storrs, E. E., Binford, C. H. \& Migaki, G. (1978). Animal model of human disease: experimental lepromatous leprosy in nine-banded armadillos (Dasypus novemcinctus Linn). American Journal of Pathology 92, 813-816.

WORLD HEALTH ORGaNIZATION (1980). UNDP/World Bank/WHO Special Programme for Research and Training in Tropical Diseases. Report of the Fifth Meeting of the Scientific Working Group on the Immunology of Leprosy (IMMLEP). TDR/IMMLEP-SWG(5)/80.3, Annex 4. Geneva: WHO. 